\title{
A survey of GP views on intra-uterine contraception
}

\author{
Sunanda Gupta, MRCOG, MFFP \\ Consultant in Community Gynaecology, Forest Healthcare NHS Trust, London, UK
}

John E Miller, DRCOG, MRCGP, MFFP

Principal in General Practice, Bridge House Surgery, Cheadle Hulme, Cheshire, UK

(Accepted June $\left.16^{\text {th }}, 1999\right)$

\section{Summary}

Aims. To investigate knowledge and attitudes towards intra-uterine contraception.

Design. Anonymous postal survey of 441 GPs (153 female and 288 male GPs) from the FHSA register in Stockport and Manchester.

Setting. General practices in Stockport and Manchester. Main outcome measure. Response to a series of questions concerning attitudes and knowledge of intra-uterine contraception.

Results. One hundred and forty-two responses were received, giving a $35 \%$ response rate. Thirty-four percent of responding GPs did not fit intra-uterine devices (IUDs), with only $10 \%$ fitting more than 30 a year. There was a significant trend against IUD fitting by male GPs and GPs aged $<40$ years. Younger GPs with $<10$ years experience were significantly more aware of the reliability of intra-uterine contraception, but perceived IUD fitting as inconvenient for both the patient and the doctor. Female GPs had better knowledge and more positive attitudes to IUDs than male GPS.

Conclusion. GPs may have difficulties in maintaining expertise. Primary care groups may opt to concentrate fittings in a few expert practices, or refer women to centrally based family planning clinics for IUD fitting.

\section{Key words}

attitudes; intra-uterine contraception; knowledge

\section{Key message points}

- A large proportion of responding GPs did not fit IUDs, and some gaps in knowledge were identified.

- Female GPs fitted more IUDs than male GPs and this correlated with positive knowledge and attitude.

- Young GPs ( $<40$ years of age) and recent graduates ( $<10$ years work experience) were the most knowledgeable, but this did not correlate with positive attitudes.

- Difficulties in maintaining expertise need to be addressed. Selected GP expert practices and FP clinics may be ideally placed for IUD fittings.

- With a low response rate it is prudent to refrain from drawing too many conclusions.

\section{Introduction}

Although large multicentre international studies continue to confirm that IUDs are both safe and effective, surveys in England and Wales indicate that the IUD may be underused $(5 \%) .{ }^{1}$ Uptake is $33 \%$ in Russia, $20 \%$ in Scandinavian countries, $15 \%$ in the Czech Republic, $11 \%$ in Slovenia, $6 \%$ in Germany, $5 \%$ in Belgium ${ }^{2}$ and $<2 \%$ in USA. ${ }^{3}$ This is despite information on improved efficacy and safety. ${ }^{4,5}$ Physicians' knowledge and attitudes influence how the IUD is presented to the user, and choice is determined also by what women may perceive as the advantages and disadvantages of this method. We carried out a postal survey to investigate and explore the attitudes and beliefs on intra-uterine contraception among GPs.

\section{Method}

A structured three-page postal questionnaire was mailed to all 441 practising GPs on FHSA mailing lists in Manchester and Stockport. Thirty-three were excluded from the above sample because they had either moved, retired or were deceased, leaving 408 possible respondents. Of these, 142 responses were obtained giving a response rate of $35 \%$. One open question was also included on 'What is your first choice IUD?' Numerical values were assigned to the responses, which were coded. The data were entered onto a computerised database. Statistical analysis was carried out with SPSS for Windows 6.1. Most questions had categorical answers. Results could therefore be analysed using $\chi^{2}$ tests.

\section{Results}

The sample included $56 \%$ women and $44 \%$ men. Seventyeight of 153 female GPs responded, giving a response rate of $56 \%$. Sixty of 288 male GPs responded, giving a $21 \%$ response rate from male GPs. The demographic details are shown in Table 1.

Table 1 Demographic data of GPs

\begin{tabular}{|c|c|c|}
\hline & Number & $\%$ \\
\hline \multicolumn{3}{|l|}{ Age $(n=141)$} \\
\hline$<30$ years & 11 & 8 \\
\hline $31-40$ years & 54 & 38 \\
\hline $41-50$ years & 48 & 34 \\
\hline$>50$ years & 28 & 20 \\
\hline \multicolumn{3}{|l|}{$\operatorname{Sex}(n=138)$} \\
\hline Male & 60 & 44 \\
\hline Female & 78 & 56 \\
\hline \multicolumn{3}{|l|}{ Ethnic background $(\mathrm{n}=137)$} \\
\hline Caucasian & 107 & 81 \\
\hline Asian & 31 & 19 \\
\hline Other & & \\
\hline \multicolumn{3}{|l|}{ Family planning $(\mathrm{FP})$ training $(\mathrm{n}=120)$} \\
\hline No FP qualification & 15 & 12.5 \\
\hline Certification/Training JCC Certificate & 105 & 88 \\
\hline \multicolumn{3}{|l|}{ Work experience $(\mathrm{n}=138)$} \\
\hline$<5$ years & 9 & 6 \\
\hline $6-10$ years & 30 & 21 \\
\hline $11-20$ years & 62 & 45 \\
\hline$>20$ years & 37 & 27 \\
\hline
\end{tabular}

$\mathrm{n}=$ number of responses

IUD fitting and use of paracervical block analgesia In answer to the question 'how frequently do you fit an IUD?' $34 \%$ of the respondents did not fit IUDs, with only $10 \%$ fitting $>30$ annually (Table 2 ). GPs $>40$ years old were more likely to fit IUDs than GPs $<40$ years old $\left(\chi^{2} 4.43\right.$, $\mathrm{p}=0.04)$. More female GPs were likely to fit IUDs than male GPs, and this difference was significant $\left(\chi^{2} 4.25\right.$, $\mathrm{p}=0.04)$. The response to the question how frequently might you use paracervical block analgesia for IUD fitting 
Table 2 How frequently do you fit an IUD and how frequently might you use paracervical block for IUD fitting in your practice? (Response to Q $9 \& 10)$

IUD fitting Number of responses \%
(out of 140)

Number of responses

$\begin{array}{lll}\text { None } & 47 & 34 \\ <30 \text { per year } & 79 & 56 \\ >30 \text { per year } & 14 & 10\end{array}$

Use of paracervical

Block

$\begin{array}{lr}\text { Never } & 119 \\ \text { In }<1 \text { in } 10 \text { fitting } & 13\end{array}$

very rarely

in your practice' indicated that $87 \%$ of respondents never use local anaesthetic techniques.

\section{Attitudes to intra-uterine contraception}

In answer to questions relating to attitudes, $64 \%$ of respondents had a high threshold, or were ambivalent, to the use of IUDs by nulliparous girls, with $26 \%$ willing to fit an IUD in nulliparous girls who choose to have one (Table 3 ). Respondents were unanimous in their belief that the risks of IUD fitting do not outweigh benefits (Table 4).

Table 3 IUD fitting in a nulliparous woman (Response to Q3)

\begin{tabular}{lcc}
\hline & Number & Percentage \\
\hline Yes if no CI and patient choice & 37 & $26 \%$ \\
Low threshold if no CI and patient choice & 11 & $8 \%$ \\
No/ (high threshold) & 87 & $61 \%$ \\
Don't know & 7 & $5 \%$ \\
\hline
\end{tabular}

$\mathrm{CI}=$ Contraindication

Attitudes analysed according to work experience, age, sex and family planning training revealed that more male respondents than female respondents perceived the IUD as an invasive method for women to choose $\left(\chi^{2} 6.472(2)\right.$, $\mathrm{p}=0.04$; Table 5). More recent graduates (with work experience $<10$ years) compared to GPs with $>10$ years experience believed that IUD fitting is an inconvenient procedure for patients $\left(\chi^{2} 5.65(2), \mathrm{p}=0.06\right)$ and that it is also inconvenient for doctors. $\left(\chi^{2} 8.19(2), \mathrm{p}=0.01\right.$; Tables 6 and 7). More respondents $<40$ years old (52\%) compared to respondents $>40$ years old believed that IUD fitting is inconvenient for the patient. More male respondents believed that there is a direct association between IUD use and infertility $\left(\chi^{2} 13.090(2), p=0.001\right)$.

No other significant differences in attitudes by differential of sex, age, work experience or family planning training were identified.

\section{Knowledge of intra-uterine contraception}

Forty percent of respondents believed that the IUD is not as reliable as the combined pill or female sterilisation. Female GPs and GPs with work experience of $<10$ years were significantly more likely to agree that an IUD is as reliable as the combined pill compared to male GPs $\left(\chi^{2} 13.63(2)\right.$, $\mathrm{p}=0.003)$ and GPs with $>10$ years experience $\left(\chi^{2} 11.581(3)\right.$, $\mathrm{p}=0.008)$. GPs $<40$ years old were more likely to agree that
Table 4 Attitudes to intrauterine contraception-how do you rate each of the following statements $(1 \& 2=$ agree, $3=$ ambivalent and $4 \& 5=$ disagree) (Response to Q11)

\begin{tabular}{|c|c|c|c|}
\hline & Agree & Disagree & Ambivalent \\
\hline $\begin{array}{l}\text { Perceived inconvenient } \\
\text { procedure for doctor }(n=132)\end{array}$ & $42(32 \%)$ & $44(48 \%)$ & $26(20 \%)$ \\
\hline $\begin{array}{l}\text { Perceived inconvenient } \\
\text { procedure for client }(n=132)\end{array}$ & $58(44 \%)$ & $34(26 \%)$ & $40(30 \%)$ \\
\hline $\begin{array}{l}\text { Perceived as an invasive } \\
\text { procedure for women to } \\
\text { choose }(\mathrm{n}=132)\end{array}$ & $47(35 \%)$ & $55(42 \%)$ & $30(23 \%)$ \\
\hline $\begin{array}{l}\text { Direct association between } \\
\text { IUD and infertility }(\mathrm{n}=130)\end{array}$ & $29(22 \%)$ & $62(48 \%)$ & $39(30 \%)$ \\
\hline $\begin{array}{l}\text { Risks of fitting an IUD } \\
\text { outweigh the benefits }(n=130)\end{array}$ & $13(10 \%)$ & $107(81 \%)$ & $12(9 \%)$ \\
\hline $\begin{array}{l}\text { Screening is of value irrespective } \\
\text { of background prevalence of } \\
\text { Chlamydia }(\mathrm{n}=142)\end{array}$ & $9(7 \%)$ & $42(32 \%)$ & $9(6 \%)$ \\
\hline
\end{tabular}

$\mathrm{n}=$ number of responses

the IUD is as reliable as the Pill than GPs $>40$ years old $\left(\chi^{2} 2.6(3), p=0.006\right)$. Table 8 relates to questions testing the knowledge of GPs.

Sixty-two percent of responding GPs believed that the Gynae T380 ${ }^{\mathrm{TM}}$ IUD is effective for only 3-5 years. More female respondents than male respondents got the correct response of 8-10 years $\left(\chi^{2} 22.196(3), p=<0.01\right)$.

When asked 'What is your first choice IUD and why?' (response to question 5), 30\% of respondents answered Nova $\mathrm{T}^{\mathrm{TM}}$. The reasons given for this choice over other IUDs were: familiarity, habit, easy fitting technique and that the practice got the best deal from the manufacturers Significantly more female respondents compared to male respondents would remove an IUD fitted after the fortieth birthday 1 year after the menopause $\left(\chi^{2} 11.915\right.$ (1), $\mathrm{p}=<0.01$ ) (Table 5). Overall the IUD was felt to be cost effective, but $20 \%$ of respondents with no family planning training felt it was not cost effective compared with only $2 \%$ of respondents who had the Diploma certification $\left(\chi^{2}\right.$ 9.54(2), $\left.\mathrm{p}=0.008\right)$. The risk of pelvic inflammatory disease (PID) up to 2 months after fitting an IUD was recognised as significant by more GPs with MRCOG / DRCOG than those with family planning certificates $\left(\chi^{2} 5.492, \mathrm{p}=0.06\right)$.

Thirty percent of doctors believe that both the Mirena ${ }^{\mathrm{TM}}$ and Gynae $\mathrm{T} 380^{\mathrm{TM}}$ are contraindicated in women with a past history of ectopic pregnancy, with GPs $<40$ years old more likely to fit a Mirena ${ }^{\mathrm{TM}}$ IUS in a woman with previous ectopic pregnancy compared to GPs $>40$ years old $\left(\chi^{2} 5.25\right.$ $(2), p=0.07)$.

\section{Discussion}

This survey is the first published survey that we are aware of to investigate the knowledge and attitudes of British GPs to intra-uterine contraception in the UK. Physician attitudes to IUDs have been studied in USA, ${ }^{4,6}$ Sweden, ${ }^{7}$ Canada $^{8}$ and Australia. ${ }^{9}$

Table 5 IUD is an invasive method for women to choose - by sex

\begin{tabular}{|c|c|c|c|c|c|c|}
\hline Sex & Agree & Ambivalent & Disagree & $\chi^{2}$ & Df & $\mathrm{p}$ \\
\hline Male & $27(46 \%)$ & $14(24 \%)$ & $18(30 \%)$ & 6.472 & 2 & $0.040 *$ \\
\hline Female & $19(27 \%)$ & $16(22 \%)$ & $36(51 \%)$ & & & \\
\hline
\end{tabular}


Table 6 IUD fitting is inconvenient for the patient - by work experience and age

\begin{tabular}{|c|c|c|c|c|c|c|}
\hline & Agree & Ambivalent & Disagree & $\chi^{2}$ & df & $\mathrm{p}$ \\
\hline \multicolumn{7}{|l|}{ Work experience } \\
\hline$<10$ years & $60 \%$ & $21 \%$ & $18 \%$ & 5.65 & (2) & $0.059 *$ \\
\hline$>10$ years & $37.8 \%$ & $36 \%$ & $26 \%$ & & & \\
\hline Age $<40$ years & $53 \%$ & $27 \%$ & $21 \%$ & & & \\
\hline Age $>40$ years & $36 \%$ & $34 \%$ & $30 \%$ & 3.62 & (2) & 0.16 \\
\hline
\end{tabular}

Table 7 IUD fitting is inconvenient for the doctor - by work experience

\begin{tabular}{llllrr}
\hline Work experience & Agree & Ambivalent & Disagree & $\chi^{2}$ & df \\
\hline$<10$ years & $51 \%$ & $16 \%$ & $32 \%$ & 8.197 & $(2)$ \\
$>10$ years & $25 \%$ & $22 \%$ & $52 \%$ & $.017 *$
\end{tabular}

The response rate of $35 \%$ was low. This may be considered a limitation in that the attitudes and practices of GPs working in teaching practices, who may have been eager to register their responses, may have been over represented. Possible explanations for the low response rate may include: the length of the questionnaire; the fact that our explanatory letter did not emphasise that this survey was not to test or audit their knowledge; questioning knowledge may have been perceived as threatening and, finally, it was not possible to send reminders to non-respondents which may otherwise have increased the response rate.

A significant trend to more female GPs fitting IUDs compared to male GPs is also borne out in the other studies. ${ }^{8,9}$ A large proportion of our responding GPs do not fit IUDs, which is likely to lead to lack of expertise. Skills can only be maintained by practice and continuing medical education (CME) on intra-uterine contraception. The overall aim of improvement in education and training is a worthwhile objective for those who fit IUDs. The Faculty of Family Planning and Reproductive Health Care of the RCOG already has a system of postgraduate education (LoC IUD) requiring re-certification every 5 years. More GPs and hospital doctors may wish to undertake the training and maintain re-certification. Alternatively, streamlined referral patterns from primary care to large centrally based dedicated specialist IUD clinics could be encouraged.

Most responding GPs did not use paracervical block analgesia prior to IUD fitting. With the advent of broader devices (Gynae $\mathrm{T} 380^{\mathrm{TM}}$, Mirena ${ }^{\mathrm{TM}}$ ) compared to Nova $\mathrm{T}^{\mathrm{TM}}$, such expertise is likely to be called for increasingly to facilitate fitting after cervical dilatation. It is disappointing that a large proportion of doctors believe that there is a direct association between IUDs and infertility, or are unsure about such an association. This is despite recent studies ${ }^{10}$ which confirm that properly screened current and former IUD users are no more likely than non-users to develop tubal adhesions, which are a major reason for tubal infertility. The RCOG recommends genital screening prior to instrumentation of the uterus, ${ }^{11}$ and most doctors screen for genital infections prior to IUD fitting.

British GPs' attitudes to IUD fittings in nulliparous women are compatible with surveys of physicians from Sweden $^{7}$ and Australia, ${ }^{9}$ and nulliparity is not considered as a contraindication to IUD fitting. ${ }^{12,13}$ It is now well accepted that a nulliparous woman in a mutually faithful sexual relationship faces minimal risks with IUDs, presumably because of less exposure to sexually transmitted infections.

Further clarification and elucidation is required regarding the mechanism of action of IUDs as $12 \%$ of responding GPs believed that the IUD acts as an abortifacient, and this may influence the attitudes of GPs to the device negatively. Current evidence does not support the commonly held belief that the IUD works usually by preventing implantation. $^{14}$

Recent studies confirm the reliability of modern IUDs and education should lead to a change in prevailing attitudes about reliability. However, most doctors, particularly if they are also family planning trained/certified, recognise the cost efficacy of this device compared to other long-term methods of contraception such as implants and injectables.

We have identified that updating should be considered with respect to more modern devices.

Forty-one percent of our respondents recommend a change of IUD within 3-5 years, even if it is fitted after the $40^{\text {th }}$ birthday. It is now accepted that a copper device fitted after the fortieth birthday can be left in place for up to a year after the menopause. This makes IUDs not only cost effective and convenient, but also reduces the likelihood of complications that may sometimes occur at, or soon after, insertion by less frequent replacement. ${ }^{5}$ A rather more surprising finding was that recent graduates $(<10$ years work experience) and GPs $<40$ years old appeared to have optimal knowledge on reliability, but fit less IUDs and feel that the IUD is inconvenient for both patients and doctors.

Although one should refrain from drawing too many conclusions from these findings, the results suggest that knowledge and attitudes are independent of each other and that knowledge does not cross correlate with IUD fitting. Similar results were reported in a recent Canadian survey. ${ }^{8}$

Gynaecological training (GPs with MRCOG/ DRCOG) associated IUD use more often with infection. Similar results were published in a survey of Finnish gynaecologists, ${ }^{7}$ who related IUD use with infection more when compared to specialists in general practice. This may be because gynaecologists see a selected group of women with suspected PID. Whatever the cause may be, the rarity of PID ${ }^{16}$ related to IUD use after careful selection needs to be stressed.

\section{Conclusion}

With a low response rate, it is prudent to refrain from drawing too many conclusions, but a large proportion of respondents did not fit IUDs, and gaps in knowledge were identified. Knowledge does not necessarily correlate with positive attitudes and more IUD fittings.

\section{Comment}

Women need balanced evidence-based information about IUD use to enable them to make effective contraceptive choices based on appropriate medical criteria. More GP 
Table 8 Knowledge of intrauterine contraception (Responses to Q1, 2, 4, 6, 7, 8 \& 12)

\begin{tabular}{|c|c|c|c|}
\hline \multicolumn{2}{|l|}{ Questions and analysable responses } & \multirow{2}{*}{ Number } & \multirow{2}{*}{$\frac{\text { Percentage }}{8}$} \\
\hline Primary action of an IUD is $(n=125)$ & Blockage of fertilisation & & \\
\hline & Abortifacient action & 17 & 12 \\
\hline & Interfere with implantation & 114 & 80 \\
\hline \multirow[t]{2}{*}{ The annual cost of IUD is high compared to other contraceptive methods ( $\mathrm{n}=132$ ) } & Higher than other methods & 9 & 7 \\
\hline & Lower than other methods & 123 & 93 \\
\hline \multirow[t]{5}{*}{$\begin{array}{l}\text { How reliable are the modern IUDs } \\
(\mathrm{n}=138)\left(\text { Gynae } \mathrm{T} 380^{\mathrm{TM}}, \text { Mirena }^{\mathrm{TM}}\right)\end{array}$} & As reliable as $\mathrm{COC} /$ & & \\
\hline & Sterilisation & 60 & 43 \\
\hline & Less reliable & 55 & 40 \\
\hline & More reliable & 13 & 9 \\
\hline & Don’t know & & \\
\hline \multirow[t]{3}{*}{ Safety of an IUD $(n=119)$} & Safe (yes) & 155 & 81 \\
\hline & Safe in monogamous relationships & 23 & 16 \\
\hline & Unsafe & 4 & 3 \\
\hline Life span Gynae T380 TM $(\mathrm{n}=136)$ & Correct response $8-10$ years & 38 & 34 \\
\hline Life span Mirena $^{\mathrm{TM}}(\mathrm{n}=135)$ & Correct response 5 years & 57 & 67 \\
\hline \multirow[t]{4}{*}{ If IUD fitted at age 41 you will $(n=125)$} & Change in $3-5$ years & 51 & 41 \\
\hline & Leave in situ for up to 1 year & & \\
\hline & after menopause & 55 & 44 \\
\hline & Change in 8 years & 10 & 8 \\
\hline \multirow[t]{3}{*}{ Perforation is a rare event $(1: 1000)$ in IUD fitting $(n=135)$} & Yes & 122 & 90 \\
\hline & No & 13 & 10 \\
\hline & Don’t know & - & - \\
\hline \multirow[t]{3}{*}{$\begin{array}{l}\text { Would you be prepared to fit a modern IUD in a woman with a previous } \\
\text { ectopic pregnancy }(n=136)\end{array}$} & Yes & 41 & 30 \\
\hline & No & 62 & 45 \\
\hline & Don't know & 33 & 24 \\
\hline \multirow[t]{2}{*}{ Risk of PID is most common up to $2 / 12$ after IUD fitting $(n=117)$} & Yes & 77 & 66 \\
\hline & No & 40 & 34 \\
\hline \multirow[t]{3}{*}{$\begin{array}{l}\text { If a Cu IUD is unavailable Mirena }{ }^{\mathrm{TM}} \text { can be used for emergency contraception } \\
(\mathrm{n}=137)\end{array}$} & Agree & 27 & 24 \\
\hline & Disagree & 38 & 33 \\
\hline & Ambiguous & 49 & 43 \\
\hline
\end{tabular}

$\mathrm{n}=$ number of responses

principals and hospital doctors may wish to avail themselves of the Faculty of Family Planning and Reproductive Health Care training and re-certification. If doctors have difficulties in maintaining expertise, primary care groups may opt to concentrate fittings in a few expert practices, or to refer women to centrally based family planning clinics.

\section{Acknowledgement}

We acknowledge gratefully the help and support provided by Dr RJE Kirkman with this survey.

Statements on funding and competing interests

Funding. Endowment research funds at Palatine Centre, Manchester. Competing interests. None declared.

References

General Household Survey. Her Majesty's Stationary Office, 1989

United Nations Department for Economic and Social Information and Policy Analysis. World Contraceptive Use (Wall Chart). New York UN, 1994.

3 Forrest JD. US women's perceptions and attitudes about the IUD. Obstet \& Gyn Survey 1996; 51(12): $530-534$.
4 Forrest JD. Acceptability of IUDs in the United States. In: Bardon CW, Mischell DR Jr, eds. Proceedings from the Fourth International Conference on IUD's. Boston: Butterworth Heinemann, 1994: 90-99.

Newton J, Tacchi D. Long term use of copper intrauterine devices - A statement from the Medical Advisory Committee of the Family Planning Association and the National Associatio of Family Planning doctors. Lancet 1990; 335: 1322-23.

Measham AR, Hatcher RA, Arnold CB. Physicians beliefs, attitudes and socio-demographic characteristics. Fam Plann 1974, 5 (4): 140-143.

Makkonen K, Hemminki E, Tuimela R. Pros and cons of intrauterine contraception - D perceptions of users and physicians differ? Scandinavian Journal of Primary Health Care

Russell ML, Love EJ. Contraceptive prescription: Physicians beliefs, attitudes and socioW. The decline in populaity of the IUD: a survey of GPattitudes and practices. New South Wales. Medical Journal of Australia 1994; 60: 19

and practices. New South Wales. Medical Journal of Australia 1994; 60: 19. RCOG Study Group. The prevention of pelvic infection. In: Templeton et al (eds). London: RCOG Press, 1996: 267-270.

WHO Scientific Report. Eligibility Guidelines for Cu IUDs 1995. Population Reports, Series B No. 6:28-30

Lete I, Morales P, de Pablo JL. Use of IUD in nulliparous women: personal experience over a 12 year period. European J of Contraception and RHC 1998; 3: 190-193.

din CW, Mische $\mathrm{DR}$ jr, eds. Proceedings from the Fourth International Conference on IUDs. Boston: Butterworth, Heinemann 1994: 44-62.

15 WHO special programme of research, development and research training in human reproduction: The TCu 380A, TCu 220C, Multiload 250 and NovaT IUDs at 3,5 and 7 year

16 Farley TMM, Rosenberg MJ, Rowe P, et al. IUD and PID: an international perspective. Lance 1992; 339: 785-788. 